\title{
Karakteristik Fluida Hidrotermal Endapan Emas Orogenik di Pegunungan Rumbia, Kabupaten Bombana, Provinsi Sulawesi Tenggara
}

\section{Characteristics of Hydrothermal Fluids Orogenic Gold Deposits in Rumbia Mountain, Bombana Regency, South East Sulawesi Province}

\author{
Hasria $^{1}$, Arifudin Idrus ${ }^{2}$, I Wayan Warmada ${ }^{2}$ \\ ${ }^{1}$ Jurusan Teknik Geologi, Universitas Halu Oleo, Kendari \\ ${ }^{2}$ Departemen Teknik Geologi, UGM, Yogyakarta \\ email: hasriageologi@gmail.com \\ Naskah diterima : 02 Oktober 2018, Revisi terakhir : 16 Mei 2019 Disetujui : 16 Mei 2019, Online : 21 Mei 2019 \\ DOI: $10.33332 /$ jgsm.2019.v20.2.111-117p
}

\begin{abstract}
Abstrak- Dewasa ini kegiatan eksplorasi emas di Indonesia tidak hanya difokuskan pada sepanjang sabuk magmatik/vulkanik, tetapi sudah mengarah pada daerah yang berbatuan metamorf. Tujuan dari penelitian ini untuk menganalisis karakteristik fluida pembentuk endapan emas pada batuan metamorf di Pegunungan Rumbia, Kabupaten Bombana Sulawesi Tenggara. Terdapat 3 (tiga) generasi urat kuarsa pembawa emas yakni urat generasi pertama yang sejajar terhadap bidang foliasi, urat generasi kedua yang memotong bidang foliasi serta urat generasi ketiga yang merupakan kuarsa \pm kalsit terlaminasi yang terbentuk pada tahap akhir dari pembentukan urat di daerah penelitian. Karakteristik fluida hidrotermal pada endapan emas di Pegunungan Rumbia, menunjukkan rentang temperatur homogenisasi (Th) pada urat kuarsa yang sejajar foliasi bervariasi yakni $220-355,30^{\circ} \mathrm{C}$ dengan salinitas $6,74-10,11$ wt. $\% \mathrm{NaCl}$ equivalen, urat kuarsa yang memotong bidang foliasi berkisar $157-255,50^{\circ} \mathrm{C}$ dengan salinitas 3,39 - 6,88 wt. \% $\mathrm{NaCl}$ equivalen, dan urat kuarsa \pm kalsit yang terlaminasi berkisar 104,40 - 265,90 $\mathrm{C}$ dengan salinitas 0,18 - 6,30 wt. $\% \mathrm{NaCl}$ equivalen. Hasil korelasi nilai temperatur pembentukan terhadap kedalaman tempat terbentuknya endapan emas orogenik diindikasikan terbentuk pada fasies sub-greenschist hingga fasies greenschist di kedalaman sekitar 4-8 kilometer serta temperatur pembentukan antara $194,40-355,30^{\circ} \mathrm{C}$ pada zona epizonal dan mesozonal. Berdasarkan karaktersitik fluida hidrotermal tersebut menunjukkan bahwa endapan emas di Pegunungan Rumbia adalah endapan emas orogenik.
\end{abstract}

Abstract- Recently, gold exploration activities are not only focused along volcanic-magmatic belt but also starting to shift along metamorphicand sedimentary terrains. The purpose of this study is to analyses the characteristics hydrothermal fluids gold deposits $t$ in the Rumbia Mountains, Bombana Regency, Southeast Sulawesi. There are three generations of veins identified including the first is parallel to the foliations, the second crosscuts the first generation of veins/foliations, and the third is of laminated deformed quartz+calcite veins at the late stage. Temperature of homogenization (Th) and salinity at Rumbia Mountain of the first vein vary from 220 to $355.30^{\circ} \mathrm{C}$ and 6.74 to $10.11 \mathrm{wt}$. \% $\mathrm{NaCl}$ eq., respectively. The second generation vein was originated at Th of 157 to $255.50^{\circ} \mathrm{C}$ and salinity of 3.39 to $6.88 \mathrm{wt} . \% \mathrm{NaCl}$ eq., whereas the third generation vein formed at lowest Th varying from 104.40 to $265.90^{\circ} \mathrm{C}$ and less saline fluid at salinity range between 0.18 and $6.30 \mathrm{wt} . \% \mathrm{NaCl}$ eq. The result of temperature formation value correlation to the depth of the formation of orogenic gold deposits in Rumbia Mountain is indicated to form on sub-greenschist to greenschist facies at depth of about 4-8 kilometers and formation temperature between 104.40 $355.30^{\circ} \mathrm{C}$ at zone epizonal and mesozonal. Based on characteristics fluids inclusion discussed above, the primary metamorphic-hosted gold mineralization type at Rumbia Mountain tends to meet the criteria of orogenic gold type.

Keyword : fluid iclusion, quartz veins, Rumbia mountain, orogenic gold deposits. 


\section{PENDAHULUAN}

Pulau Sulawesi terletak di tengah-tengah kepulauan Indonesia, dipengaruhi oleh aktivitas pergerakan lempeng dunia yakni Lempeng Benua Eurasia, Lempeng Benua Australia dan Lempeng Samudera Pasifik atau Lempeng Samudera Filipina (Gambar 1) (Hall, 1996). Posisi tersebut mengakibatkan pulau ini mempunyai, geomorfologi, stratigrafi struktur geologi yang kompleks serta komposisi litologi yang beragam. Hal inilah yang menarik para ahli ilmu kebumian dari dalam dan luar negeri untuk meneliti Pulau Sulawesi. Pulau Sulawesi merupakan pulau terbesar keempat di Indonesia setelah Pulau Sumatera, Pulau Kalimantan dan Pulau Papua yang mempunyai luas wilayah $174.600 \mathrm{~km}^{2}$.

Adapun batuan sedimen pelagik termasuk dalam Formasi Matano (Km), yang tersusun oleh batugamping laut dalam dan sisipan rijang merah (rijang radiolarian) (Hamilton, 1979; Silver dkk., 1983; Simandjuntak 1986 dalam Surono, 2013). Molasa Sulawesi tersusun atas sedimen klastik dan sedimen karbonatan. Batuan sedimen klastik mendominasi batuan penyusunnya sedangkan batuan karbonat menyebar setempat. Satuan sedimen klastik terdiri atas Formasi Langkowala, Stratigrafi regional Lengan Tenggara Pulau Sulawesi terdiri dari 3 kelompok utama batuan penyusun yaitu, Kompleks Ofiolit; Molasa Sulawesi dan Kompleks Batuan Metamorf (Surono, 2013) (Gambar 2). Kompleks Ofiolit di didominasi oleh batuan ultramafik yang terdiri dari harzburgit, dunit, werlit, lerzolit, websterit, serpentinit, dan piroksinit yang merupakan (Kundig, 1956; Simanjuntak dkk., 1993a, b, c; Rusmana dkk., 1993a, dalam Surono, 2013) Batuan ultramafik adalah merupakan Kompleks Ofiolit yang terangkat pada saat pembentukan orogenesa di Sulawesi Tenggara. Hubungan antara Kompleks Batuan Ultramafik dengan Kompleks Pompangeo adalah sentuhan tektonik. Kompleks Ofiolit ini tersesar-naikan ke atas batuan metamorf dan atau lapisan sedimen tepi benua (Surono, 2013). Batuan mafik terdiri atas gabro, basalt, dolerit, mikrogabro, dan amfibolit. Formasi Boepinang dan Pandua sedangkan satuan karbonatnya adalah Formasi Eemoiko. Formasi Langkowala terdiri atas konglomerat, batu pasir, serpih dan setempat batugamping. Formasi Boepinang tersusun oleh batu lempung pasiran, napal pasiran dan batupasir, Formasi Pandua didominasi oleh konglomerat dan batu pasir, sedangkan Formasi Eemoiko tersusun oleh batugamping (kalkarenit), batugamping koral, batupasir dan napal (Surono, 2013).

Kompleks batuan metamorf berada pada bagian ujung selatan Lengan Tenggara Pulau Sulawesi yang membentuk Pegunungan Rumbia terdiri atas sekis, kuarsit, sabak dan marmer (Simandjuntak dkk., 1993c; Rusmana., 199b dalam Surono, 2013) dan diterobos aplit dan diabas (Surono, 1986 dalam Surono, 2013). Batuan ini merupakan satuan batuan tertua yang menjadi batuan dasar (bedrock) dari Formasi Langkowala, Formasi Eemoiko dan Formasi Boepinang yang berumur lebih muda. Struktur utama yang berkembang di daerah penelitian umumnya didominasi oleh sesar geser mengiri yang berarah tenggara-barat laut (Gambar 2).

Penelitian tentang endapan emas dengan batuan induk batuan metamorf masih sangat kurang jika dibandingkan dengan penelitian endapan emas dengan batuan induk berupa vulkanik/magmatik, sehingga sangat dibutuhkan penelitian-penelitian terbaru untuk mengungkap karakteristik dan potensi pengembangannya di Indonesia, khususnya endapan emas orogenik. Demikian halnya dengan karakteristik fluida hidrotermal pada batuan metamorf juga masih kurang. Penelitian ini berlokasi di Pegunungan Rumbia yang termasuk dalam Kabupaten Bombana, Sulawesi Tenggara (Gambar 3).

\section{METODE PENELITIAN}

Metode dan tahap penelitian secara garis besar terbagi atas dua tahap yaitu :

1. Pekerjaan lapangan yaitu pengambilan data singkapan batuan dan urat kuarsa, serta dilakukan pengambilan sampel yang representatif pada urat kuarsa untuk dianalisis di laboratorium

2. Pekerjaan Laboratorium yaitu analisis petrografi inklusi fluida dan mikrotermometri yang meliputi pengukuran temperatur pelelehan dan temperatur homogenisasi pada 6 (enam) sampel urat kuarsa yang terdiri dari 3 sampel dari urat kuarsa yang sejajar bidang foliasi, 1 sampel memotong foliasi, 2 sampel urat kuarsa \pm kalsit terlaminasi. Kemudian sampel tersebut dipreparasi menjadi sayatan poles ganda (double polish section) yang dilakukan di Laboratorium Preparasi Sampel Pusat Survei Geologi (PSG) Bandung. Setelah dipreparasi, sampel tersebut kemudian dianalisis di Laboratorium Inklusi Fluida Pusat Survei Geologi (PSG) Bandung dengan menggunakan alat Linkam THM.SG 600 Freezing and Heating Stage. Analisis petrografi inklusi dilakukan untuk mengidentifikasi tipe inklusi primer, adapun penentuan nilai $\mathrm{Tm}$ dilakukan dengan cara membekukan inklusi fluida sampai $-60^{\circ} \mathrm{C}$, kemudian temperatur dinaikkan secara perlahan sampai mengalami pelelehan (melting) sehingga diperoleh nilai Tm (temperature of melting). Nilai Th (temperature of 
homogenezation) ditentukan dengan cara melakukan pemanasan pada inklusi fluida secara perlahan sampai semua gas menghilang, maka akan didapat nilai Th (temperature of homogenezation) dari inklusi fluida tersebut. Salinitas fluida dapat dihitung dengan menggunakan persamaan Bodnar (1993) dan Bodnar and Vityk (1994).

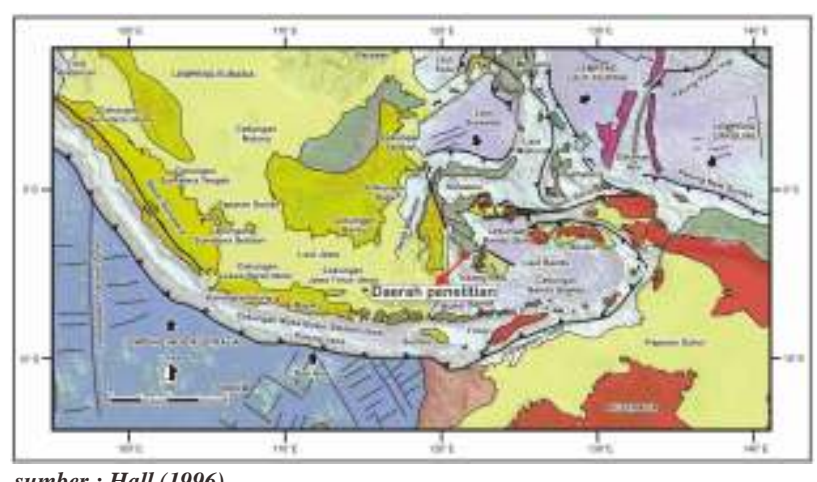

sumber : Hall (1996)

Gambar 1. Posisi Pulau Sulawesi yang terletak di tengah Kepulauan Indonesia yang dipengaruhi oleh aktivitas pergerakan tiga lempeng yang aktif saling bertumbukan.

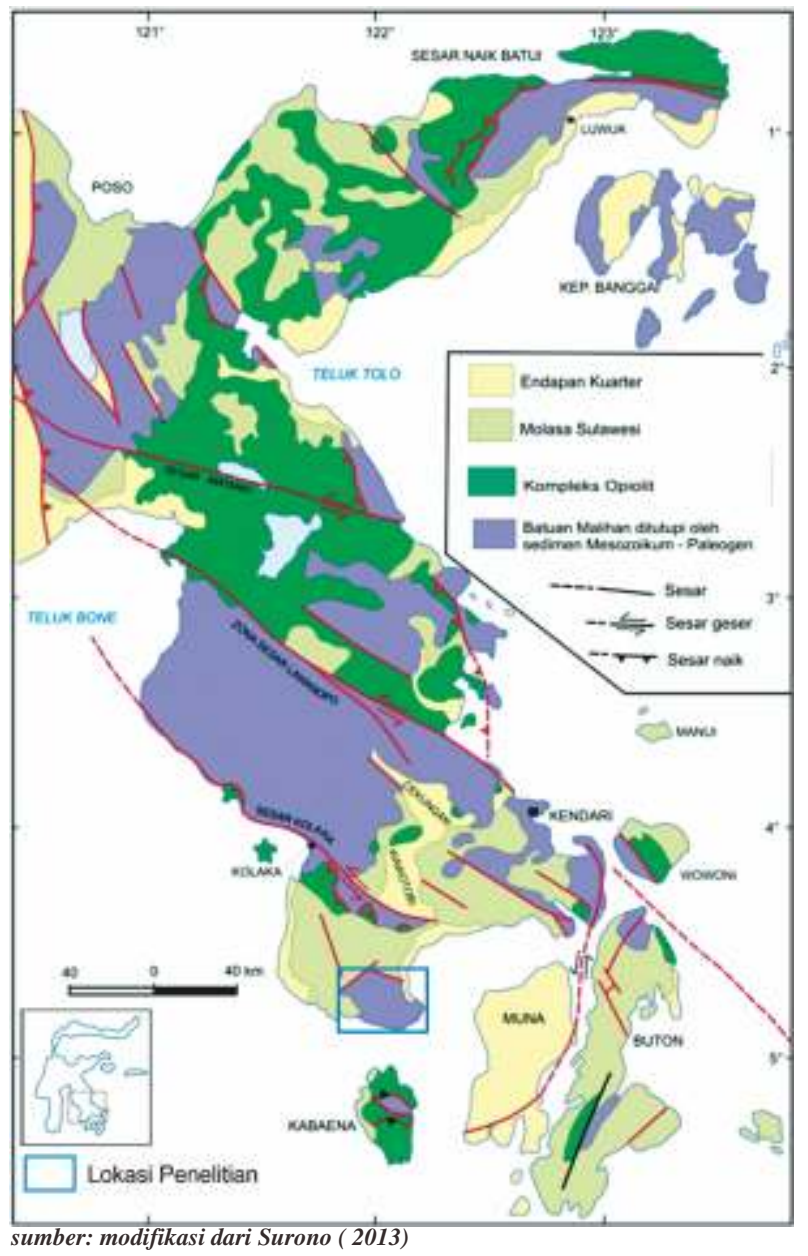

Gambar 2. Peta geologi Lengan Tenggara Pulau Sulawesi.

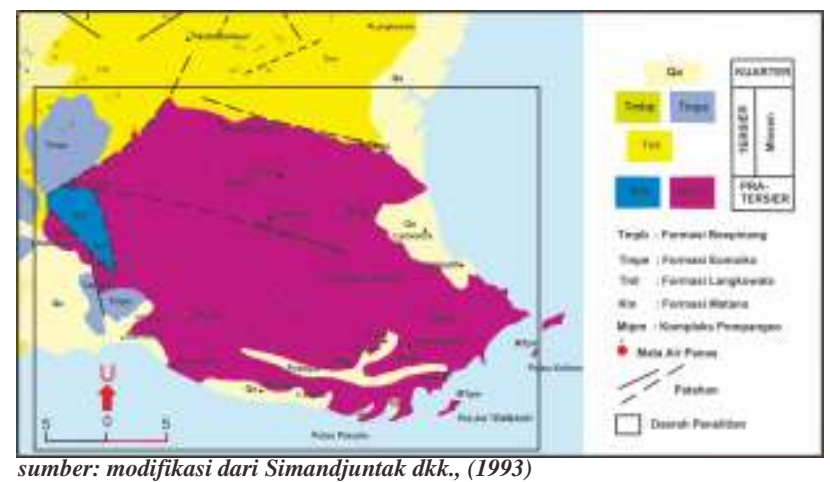

Gambar 3. Peta geologi Pegunungan Rumbia, Kabupaten Bombana, Sulawesi Tenggara.

\section{PEMBAHASAN}

\section{Karaktersitik Fluida Hidrotermal Pegunungan Rumbia}

\section{Tipe dan Tekstur urat kuarsa Pegunungan Rumbia}

Tipe urat di Pegunungan Rumbia terdiri dari 3 generasi yakni urat generasi pertama yakni urat yang sejajar terhadap bidang foliasi dan urat generasi kedua yakni urat yang memotong urat pertama dan foliasi serta urat generasi ketiga yang merupakan urat kuarsa \pm kalsit yang terlaminasi yang terbentuk pada akhir dari pembentukan urat di daerah penelitian. Urat kuarsa di daerah Penelitian umumnya telah mengalami deformasi yang lemah hingga kuat, terbreksiasi, massif, tersegmentasi dan terlaminasi yang memiliki ketebalan antara 0,2 cm sampai 56,7 cm (Gambar 4). Kadar emas dalam urat kuarsa sangat bervariasi dari di bawah ambang batas <0,0002 ppm sampai 18,4 ppm yang terdapat pada ketiga tipe generasi urat dan kadar emas tertinggi terdapat pada urat kuarsa generasi ketiga (Hasria dkk., 2017).

\section{Petrografi Inklusi Fluida Pegunungan Rumbia}

Analisis petrografi inklusi fluida di Pegunungan Rumbia (Gambar 5) hanya dilakukan pada inklusi fluida primer, dimana ukuran inklusi umumnya memiliki ukuran yang sangat kecil $(<100 \mu \mathrm{m})$ yakni 3,6-95 $\mu \mathrm{m}$. Inklusi fluida yang nampak dikategorikan ke dalam tipe inklusi dua fase (two phase inclusion) yang kaya akan cairan/liquid $\left(\mathrm{H}_{2} \mathrm{O}\right)$ dibanding vapour $\left(\mathrm{CO}_{2}\right)$ (liquid-rich) $(\mathrm{V}+\mathrm{L})$, karena kandungan liquid mencapai $>50 \%$ (Shepherd dkk., 1985). Inklusi fluida di daerah penelitian umumnya memiliki bentuk yang relatif relatif membulat, ovoidal, relatif memanjang serta tidak teratur (Gambar 5a, d, berbentuk ovoidal (Gambar 4a,c berbentuk tabular (Gambar 4d) serta berbentuk bulat (Gambar 4a). Hasil pengamatan inklusi fluida menunjukkan bahwa tidak adanya kondisi boiling di daerah penelitian. Fotomikrograf inklusi fluida menunjukkan adanya kontribusi cairan 
meteorik, dan cairan metamorfik yang membentuk urat kuarsa yang ditunjukkan oleh kehadiran $\mathrm{H}_{2} \mathrm{O}-\mathrm{NaCl} \pm$ $\left(\mathrm{CO}_{2}\right)$. Komposisi gas $\left(\mathrm{CO}_{2}\right)$ yang teranalisa dalam inklusi fluida tersebut juga mempunyai jumlah yang relatif sedikit, kemungkinan karena posisi endapan emas tipe orogenik ini berada pada level epizonal atau dekat dengan permukaan sehingga gas $\mathrm{CO}_{2}$ cenderung menghilang. Hal ini bersesuaian dengan konsep model endapan emas orogenik menurut Gebre-Mariam dkk. (1995) dan Groves dkk (1998).

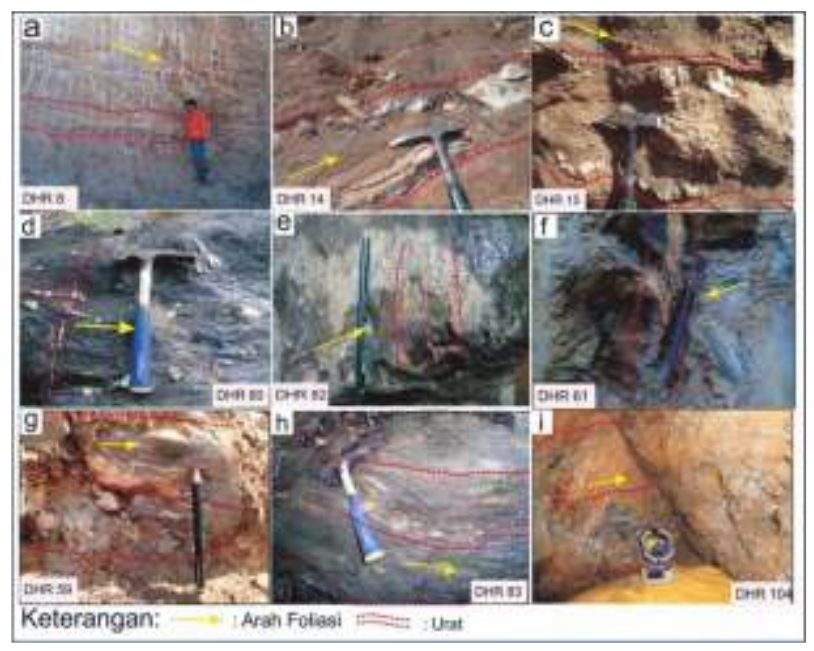

Gambar 4. Karakteristik urat kuarsa yang berasosiasi dengan mineral pembawa bijih emas, berdasarkan generasi/proses dari pembentukan urat. a) urat kuarsa yang sejajar foliasi, b) urat kuarsa masif, bercabang yang sejajar foliasi (generasi pertama), c) urat kuarsa sejajar foliasi, terdeformasi (generasi pertama), d) urat memotong foliasi yang mengalami deformasi-terbreksiasi dan massif (generasi kedua), d) urat memotong foliasi-tak beraturan/tersegmentasi (generasi kedua), e) oksidasi tinggi pada urat kuarsa yang mengalami deformasi (generasi kedua), f) urat kuarsa yang memotong foliasi dan terdeformasi, g) oksidasi tinggi pada urat kuarsa yang mengalami deformasi dan terlaminasi (generasi ketiga), h) urat kuarsa laminasi bergelombang (generasi ketiga), i) urat kuarsa laminasi sejajar hingga bergelombang (generasi ketiga).
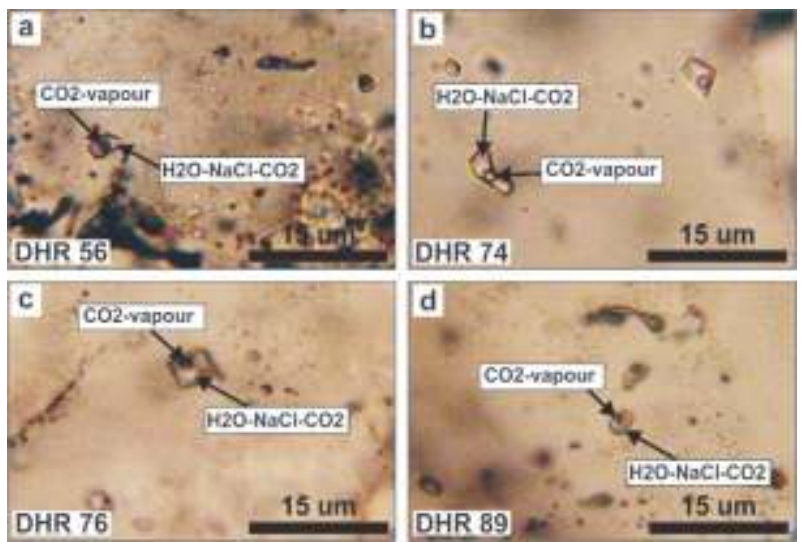

Gambar 5. Variasi morfologi inklusi fluida primer pada Pegunungan Rumbia. (a) Inklusi berbentuk relatif membulat (bawah) dan tidak teratur dan memanjang (atas). (b) Inklusi berbentuk tabular, tidak teratur (bawah) dan relatif membulat (atas). (c) Inklusi berbentuk ovoidal dan relatif membulat. (d) Inklusi berbentuk relatif membulat, ovoidal dan tidak teratur. L: fase cair $($ liquid $)=\mathrm{H}_{2} \mathrm{O}$, V: fase uap $($ vapor $)=\mathrm{CO}_{2}$.

\section{Mikrotermometri Inklusi Fluida Pegunungan Rumbia}

Hasil pengukuran mikrotermometri dan interpretasi salinitas, maka diperoleh rentang temperatur homogenisasi (Th) inklusi fluida pada urat kuarsa yang sejajar foliasi bervariasi yakni $220-355,30^{\circ} \mathrm{C}$ dengan salinitas $6,74-10,11 \mathrm{wt}$. \% $\mathrm{NaCl}$ equivalen, urat kuarsa yang memotong bidang foliasi berkisar $157-255,50^{\circ} \mathrm{C}$ dengan salinitas 3,39-6,88 wt. \% $\mathrm{NaCl}$ equivalen, dan urat kuarsa \pm kalsit yang terlaminasi berkisar 104,40 $265,90^{\circ} \mathrm{C}$ dengan salinitas $0.18-6,30$ wt. $\% \mathrm{NaCl}$ equivalen (Tabel 1). Adapun nilai rerata temperatur homogenisasi (Th) masing-masing tipe urat secara berurutan adalah $271,67^{\circ} \mathrm{C}$ dengan salinitas 9,0 wt. $\%$ $\mathrm{NaCl}$ equivalen; $228,49^{\circ} \mathrm{C}$ dengan salinitas 6,08 wt. $\%$ $\mathrm{NaCl}$ equivalen dan $194,21^{\circ} \mathrm{C}$ dengan salinitas 3,91 wt.\% $\mathrm{NaCl}$ equivalen. (Tabel 1). Dari hasil analisis tersebut urat yang sejajar foliasi, urat kuarsa yang memotong foliasi maupun urat kuarsa \pm kalsit yang terlaminasi juga menunjukkan adanya perbedaan nilai $\mathrm{Tm}$, Th dan salinitas yang cukup signifikan serta menunjukan karakteristik yang berbeda antara ketiga tipe urat tersebut.

Tabel 1. Data hasil analisis inklusi fluida urat kuarsa Pegunungan Rumbia

\begin{tabular}{|c|c|c|c|c|c|c|c|c|c|}
\hline No. & $\begin{array}{l}\text { Kode } \\
\text { Kampel }\end{array}$ & Generasi & $\begin{array}{l}\mathrm{Tm}^{\circ} \mathrm{C} \\
\text { (entang }\end{array}$ & $\mathrm{Tm}^{\circ} \mathrm{C}$ & $\mathrm{Th}^{\circ} \mathrm{C}$ & $\mathrm{Th}^{\circ} \mathrm{C}$ & Salinitas (rentang) & Salinitas (rerata) & n \\
\hline 1. & $\begin{array}{l}\text { Sampel } \\
\text { DHR } 22\end{array}$ & $\begin{array}{l}\text { unarat } \\
\text { Generasi }\end{array}$ & $\begin{array}{l}-5,800--6,60 \\
-50,60\end{array}$ & (rerataly & $\begin{array}{l}\text { (rentang }) ~ \\
318,00-355,30\end{array}$ & & $\frac{1 . \%}{8,95-9,98}$ & 9,34 & 20 \\
\hline 2. & DHR 56 & Generasi & $-4,20--6,60$ & $-5,64$ & $220,00-295,00$ & 248,41 & $6,74-9,98$ & 8,72 & 39 \\
\hline 3. & $\begin{array}{l}\text { DHR } 74 \\
\end{array}$ & Generasi & $-0,50-3,3,3$ & $-2,15$ & $104,40-248,00$ & 174,97 & $\overline{0.88-5,41}$ & 3,60 & $\overline{34}$ \\
\hline 4. & DHR 76 & ke-3 & $-4,90--6,70$ & $-6,01$ & $224,00-269,00$ & 252,79 & $7,73-10,11$ & 9,21 & 20 \\
\hline 5. & DHR 87 & Generasi & $-2,00-4,30$ & $-3,77$ & $157,00-255,50$ & 215,23 & $3,39-6,88$ & 6,08 & 20 \\
\hline 6. & DHR 89 & $\begin{array}{l}\text { Generasi } \\
\text { ke.3asi }\end{array}$ & $-0,10--3,90$ & $-2,70$ & $1655,00-265,90$ & 204,09 & $0,18-6,30$ & 4,45 & $\frac{20}{20}+x-1$ \\
\hline
\end{tabular}

Data hasil pengukuran mikrotermometri dan interpretasi salinitas tersebut, selanjutnya dimasukkan ke dalam kurva histogram untuk menentukan kisaran temperatur homogenisasi dan salinitas yang berfekuensi tinggi (median) pada setiap generasi urat yang ada di daerah penelitian (Gambar 6 dan Gambar 7). Berdasarkan grafik histogram (Gambar 5) tersebut menunjukkan bahwa nilai (Th) dengan nilai kemunculan frekuensi tertinggi (modus) pada urat kuara sejajar foliasi adalah sebesar $240-250^{\circ} \mathrm{C}$, urat kuarsa yang memotong foliasi sebesar $215-220^{\circ} \mathrm{C}$ dan urat kuarsa \pm kalsit sebesar $175-180^{\circ} \mathrm{C}$. Adapun grafik histogram (Gambar 6) yang menyatakan hubungan antara salinitas terhadap frekuensi menunjukkan bahwa nilai kemunculan frekuensi tertinggi untuk salinitas setiap generasi urat menunjukkan nilai yang berbeda yakni urat yang sejajar foliasi sebesar 9,5-10 wt.\% $\mathrm{NaCl}$ equivalen, urat yang memotong foliasi sebesar 6,5-7,0 wt.\% $\mathrm{NaCl}$ equivalen dan urat laminasi sebesar 4,5-5,0 wt.\% $\mathrm{NaCl}$ equivalen. 


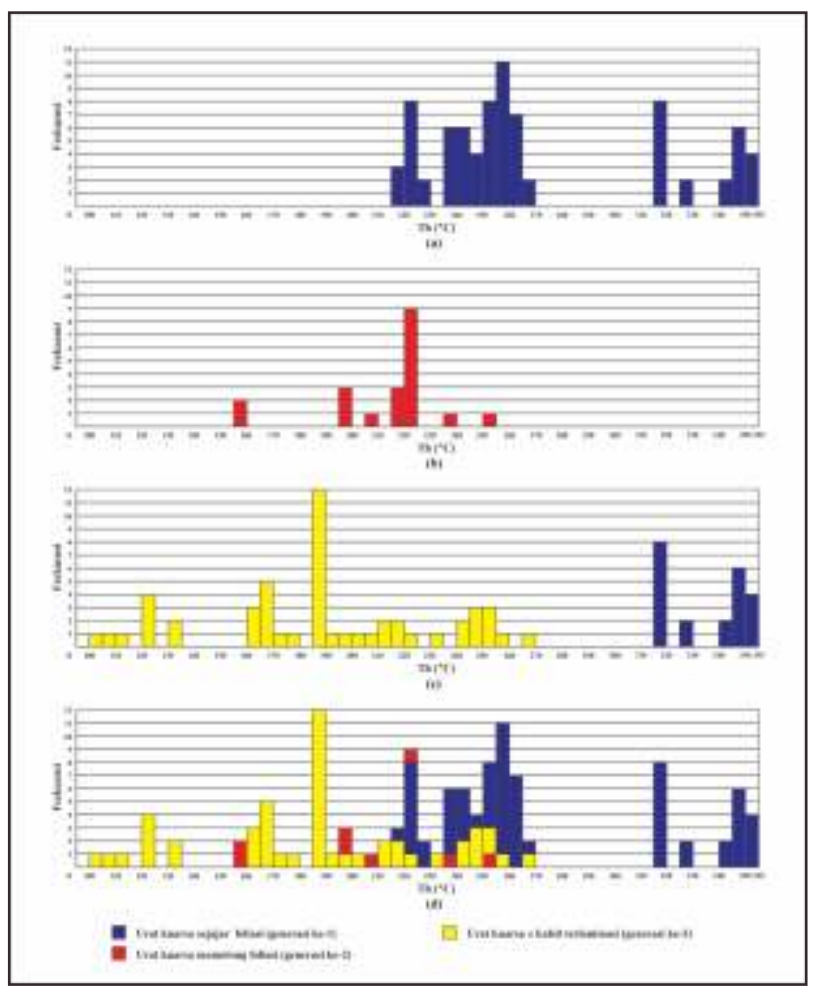

Gambar 6. (a,b,c).Histrogram nilai temperatur homogenisasi (Th) pada masing-masing tipe urat; dan (d) Histogram Th pada tiga tipe urat di Pegunungan Rumbia.

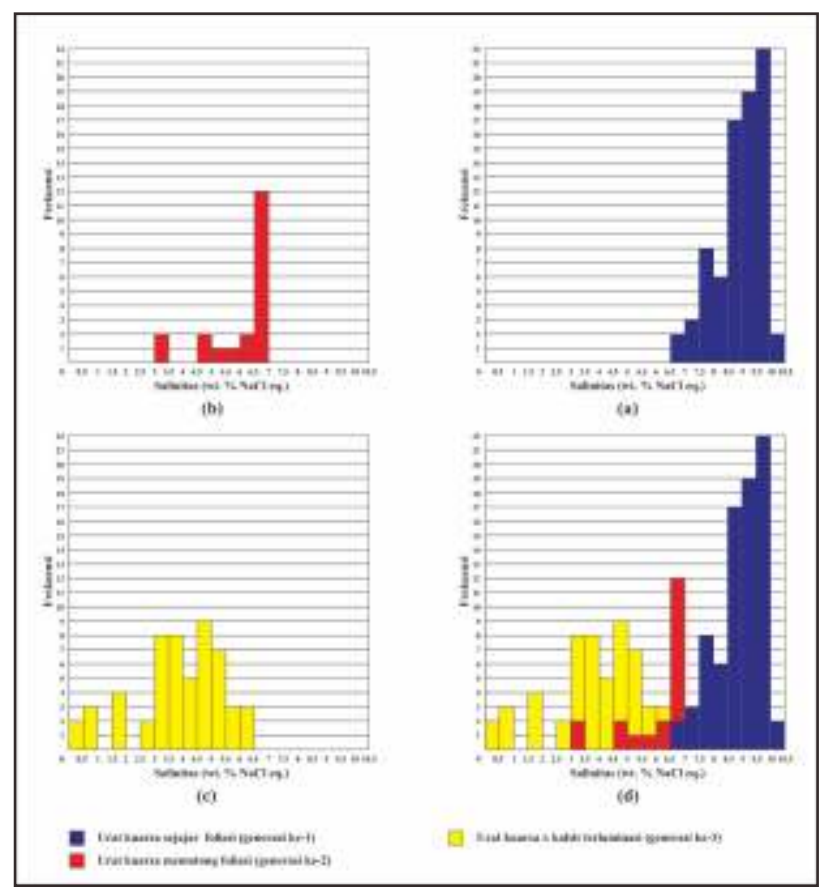

Gambar 7. (a,b,c) Histrogram nilai temperatur homogenisasi (Th) pada masing-masing tipe urat; dan (d) Histogram Th pada tiga tipe urat di Pegunungan Rumbia.
Berdasarkan hasil analisis dari kedua histogram (Gambar 6 dan Gambar 7), maka dapat disimpulkan bahwa umumnya nilai temperatur homogenisasi (Th) dan salinitas urat yang sejajar foliasi (generasi ke-1) mempunyai nilai yang relatif lebih tinggi jika dibandingkan dengan urat yang memotong foliasi dan urat kuarsa \pm kalsit terlaminasi. Pada Gambar 6, nilai temperatur homogenisasi (Th) generasi ke-1 (sejajar foliasi) nampak terdapat dua (2) kelompok populasi, tetapi pada dasarnya nilai tersebut masih merupakan nilai Th pada urat generasi yang sama. Nilai Th $310^{\circ} \mathrm{C}$ pada Gambar 6, walaupun memiliki nilai lebih tinggi dari modus, tetapi pada dasarnya nilai tersebut masih tergolong dalam urat generasi ke-1 dan masih termasuk dalam temperatur pembentukan endapan emas orogenik (Gebre-Mariam., dkk, 1995). Adapun urat kuarsa yang memotong foliasi (generasi ke-2) mempunyai nilai Th dan salinitas yang lebih rendah dibandingkan dengan urat kuarsa yang sejajar foliasi tetapi lebih tinggi dibandingkan dengan urat kuarsa \pm kalsit terlaminasi, sedangkan urat kursa \pm kalsit yang terlaminasi (generasi ke-3) yang merupakan fase akhir dari pembentukan endapan di daerah penelitian mempunyai nilai Th dan salinitas yang relatif lebih rendah dari semua tipe urat.

\section{Evolusi Fluida dan Tipe Endapan Pegunungan Rumbia.}

Berdasarkan analisis inklusi fluida, maka temperatur pembentukan endapan berkisar antara $104,40-355,30^{\circ} \mathrm{C}$ dengan salinitas berkisar $0,18-10,11$ wt. $\% \mathrm{NaCl}$ equivalen.

Penentuan evolusi fluida dilakukan dengan pengeplotan nilai salinitas terhadap temperatur homogenisasi (Th) kemudian dikorelasikan terhadap diagram kecenderungan salinitas-Th terkait proses evolusi fluida endapan berdasarkan Shepherd dkk. (1995) (Gambar 8).

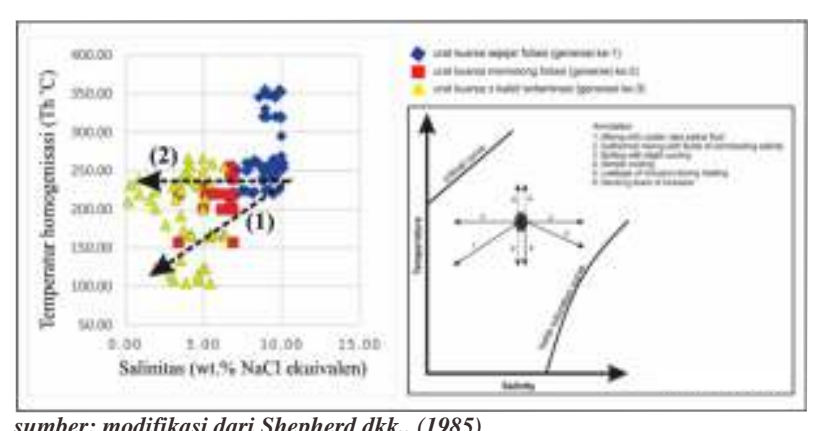

sumber: modifikasi dari Shepherd dkk., (1985)

Gambar 8. Hubungan antara temperatur homogenisasi (Th oC) dan salinitas dari 3 sampel tipe urat Pegunungan Rumbia. 
Mengacu pada Gambar 8 di atas, nampak bahwa temperatur pembentukan dan salinitas fluida endapan emas orogenik di lokasi penelitian menunjukkan adanya trend penurunan secara perlahan dari urat generasi ke-1, ke-2 hingga ke-3. Jika dikorelasikan dengan evolusi fluida endapan berdasarkan Shepherd dkk. (1995), maka evolusi fluida endapan yang ada di daerah penelitian terbagi dari 2 (dua) fase yakni fase pertama (1) adalah isothermal mixing with fluids of constracting salinity dan fase kedua (2) adalah fase mixing with cooler, less saline fluids. Berdasarkan evolusi endapan tersebut, maka sumber fluida endapan diperkirakan berasal dari campuran air metamorfik dan meteorik karena mempunyai temperatur dan salinitas yang menengah hingga rendah yakni temperatur $104,40-355,30^{\circ} \mathrm{C}$ dengan salinitas $0,18-10,11$ wt. \% $\mathrm{NaCl}$ equivalen.

Berdasarkan hasil analisis inklusi fluida tersebut di atas, maka penentuan kedalaman tidak dapat ditentukan berdasarkan hasil analisis tersebut karena tidak adanya kondisi boiling. Penentuan kedalaman endapan ini dilakukan dengan cara mengkorelasikan nilai temperatur yang diperoleh dengan nilai temperatur pembentukan menurut Groves, 1993; Groves dkk., 1998, 2003; dan Gebre-Mariam., dkk, 1995; Goldfarb dan Groves, 2015 (Gambar 9).

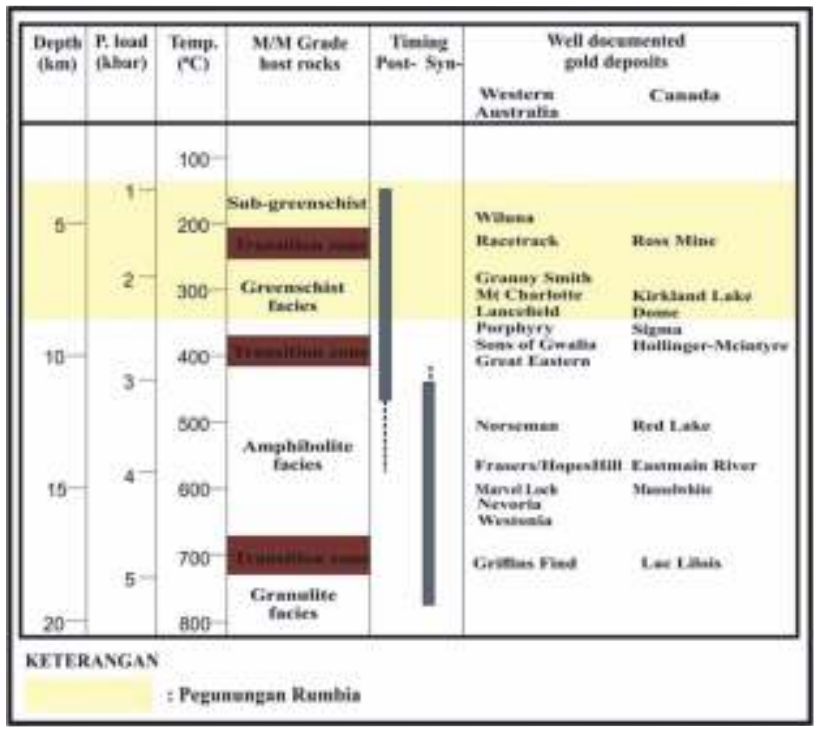

sumber: modifikasi Groves, 1993; Groves dkk., 1998; 2003 dan Gebre-Mariam dkk., 1995; Goldfarb dan Groves, 2015.

Gambar 8.Zona keberadaan endapan emas orogenik Pegunungan Rumbia dengan beberapa endapan emas orogenik yang terdapat di Australia Barat dan Canada berdasarkan korelasi nilai temperatur pembentukan.
Hasil korelasi nilai temperatur pembentukan terhadap kedalaman tempat terbentuknya endapan emas orogenik, maka diindikasikan terbentuk pada fasies subgreenschist hingga fasies greenschist di kedalaman sekitar 4-8 kilometer serta temperatur pembentukan antara $104,40-355,30^{\circ} \mathrm{C}$ dan berada pada berada pada zona epizonal dan mesozonal, sehingga diinterpretasikan bahwa endapan emas orogenik ini sama dengan endapan emas orogenik Wiluna, Racetrack, Granny Smith, Mt Charlotte dan Lancifield di Australia Barat dan Ross Mine, Kirkland Lake dan Dome di Canada (Gebre-Mariam dkk., 1995) dan waktu terbentuknya mineralisasi emas hidrotermal terjadi bersamaan dengan proses metamorfime berlangsung (Groves, 1993).

\section{KESIMPULAN}

Terdapat 3 generasi urat yang teridentifikasi di lokasi penelitian yakni urat generasi ke-1 yang merupakan urat yang sejajar foliasi, generasi ke-2 yakni urat yang memotong foliasi, dan generasi ke-3 yaitu urat kalsitkuarsa, merupakan yang terbentuk pada fase akhir dari endapan emas orogenik di lokasi penelitian.

Evolusi fluida endapan emas orogenik yang ada di lokasi penelitian terbagi 2 (dua) fase yaitu fase isothermal mixing with fluids of constracting salinity, dan mixing with cooler, less saline fluids.

Temperatur pembentukan terhadap kedalaman tempat terbentuknya endapan emas orogenik, maka diindikasikan terbentuk pada fasies sub-greenschist hingga fasies greenschist di kedalaman sekitar 4-8 kilometer serta temperatur pembentukan antara 104,40$355,30^{\circ} \mathrm{C}$ dan berada pada berada pada zona epizonal dan mesozonal. Adapun fluida endapan diperkirakan berasal dari cairan metamorfik serta sedikit bercampur dengan cairan magmatik maupun cairan meteorik. Berdasarkan karakteristik fluida hidrotermal, maka diindikasikan bahwa endapan emas di daerah penelitian adalah endapan emas orogenik yang dapat dijadikan target target eksplorasi baru sumberdaya emas primer pada batuan non vulkanik (batuan metamorf) karena selama ini eksplorasi emas selalu berhubungan dengan aktivitas vulkanik (batuan gunungapi) sehingga dapat memaksimalkan penemuan dan pemanfaatan sumberdaya emas yang dimiliki di Indonesia. 


\section{UCAPAN TERIMAKASIH}

Terimaksih kami sampaikan kepada Dinas Pertambangan Sulawesi Tenggara karena telah memberikan izin penelitian di Pegunungan Rumbia, Bombana. Terimakasih kepada PT. Panca Logam Makmur (PLM) atas bantuan fasilitas dalam pengambilan sampel di lapangan. Terimakasih kepada Laboratorium Preparasi Sampel Pusat Survei Geologi dan Laboratorium Inklusi Fluida Pusat Survei Geologi (PSG) Bandung. Terimaksih kepada mahasiswa Teknik Geologi Universitas Halu Oleo yang telah ikut membantu pengambilan sampel di lapangan. Ucapan terimaksih juga kami sampaikan kepada Bapak Dr. La Ode Ngkimani, S.Pd., M.Si dan Bapak Suryawan Asfar, S.T., M.Si atas bantuan fasilitas dalam pengambilan sampel di lapangan.

\section{ACUAN}

Hall, R. (1995). Plate tectonic reconstructions of the Indonesian region. Indonesian Petroleum Association, Proceedings 24th Annual Convention, 24, 71-84.

Bodnar, R.J. and Vityk, M.O., 1994. Interpretation of Microthermometric Data for $\mathrm{H}_{2} \mathrm{O}-\mathrm{NaCl}$ Fluid Inclusions. In. De Vivo, B. and Frezzotti, M.L. (Eds.). Fluid Inclusions in Mineral, Methods and Applications, Published by Virginia Tech, Blacksburg, VA, 117-130.

Bodnar, R.J., 1993. Revised Equation and Table for Determining the Freezing Point Depression of H2O-Nacl Solution. Geochimica Et Cosmochimica Acta, 57, 683-684.

Gebre-Mariam, M., Hagemann, S.G., and Groves, D.I., 1995. A Classification Scheme for Epigenetic Archaen LodeGold Deposits. Mineralium Deposits, 30, 408-410.

Goldfarb, R.J., and Groves, D.I., 2015. Orogenic Gold : Common or Evolving Fluid and Metal Sources Through Time. Lithos, 233, 2-26.

Groves, D.I., 1993, The crustal continuum model for late-Archaean lodegold deposits of the Yilgarn block, Western Australia: Mineralium Deposita, 28, 366-374.

Groves, D.I., Goldfarb, R.J., Gebre-Mariam, M., Hagemann, S.G., and Robert, F., 1998. Orogenic Gold Deposits: A Proposed Classification in the Context of Their Crustal Distribution and Relationship to Other Gold Deposit Types: Ore Geology Reviews, 13, 7-27.

Groves, D.I., Goldfarb, R.J., Robert, F., and Hart, C.J.R., 2003. Gold Deposits in Metamorphic Belts: Overviuw of Current Understanding, Outstanding Problems, Future Research, and Exploration Significance. Economic Geology, 98, 1-29.

Hasria., Idrus, A., Warmada, I.W. 2017. The Metamorphic Rocks-Hosted Gold Mineralization At Rumbia Mountains Prospect Area In The Southeastern Arm Of Sulawesi Island, Indonesia. Journal of Geoscience, Engineering, Environment, and Technology, 2, 213-227.

Shepherd,T.J., Rankin, A.H. and Alderton, D.H.M. 1985. A Practical Guide to Fluid Inclusion Studies: Blackie and Son Ltd., Glasgow, 239p.

Simandjuntak, T.O., Surono, dan Sukido. 1993. Peta Geologi Lembar Kolaka, Sulawesi, Skala 1:250.000. Pusat Penelitian dan Pengembangan Geologi, Bandung.

Surono. 2013a. Geologi Lengan Tenggara Sulawesi. Badan Geologi, Kementerian Energi dan Sumber Daya Mineral. Bandung, 169p. 